\title{
Time trends in single versus concomitant neck and back pain in finnish adolescents: results from national cross-sectional surveys from 1991 to 2011
}

\author{
Minna Kristiina Ståhl ${ }^{1,2^{*}}$, Ashraf Abdel Salam El-Metwally ${ }^{3,4}$ and Arja Hannele Rimpelä5,6
}

\begin{abstract}
Background: Previous studies, in late 20th century, suggest an increase in the prevalence of neck pain and low back pain among children and adolescents, when neck and low back pain were studied separately. This study investigated time trends in adolescent spinal pain between 1991 and 2011 by classifying pain into the following three classes: neck pain alone, low back pain alone, and concomitant neck and low back pain.
\end{abstract}

Methods: Representative samples of 12 to 18-year-old Finns were sent a questionnaire in 1991, 1999, 2001, 2003, 2005, 2007, 2009 and 2011. Information was gathered about the frequency of neck and low back pain with a six-month recall period. Statistical methods used included descriptive analysis, and generalized linear models.

Results: The total number of respondents in these eight comparable cross-sectional surveys was 51044 with a response proportion of 64\%. The prevalence of concomitant neck and low back pain showed a steady increase from 1991 to 2009/2011; the prevalence almost quadrupled among 12-14-year-olds girls (from 2\% to 7.5\%), and more than doubled among 12-14-year-old boys (from 1.6\% to 3.8\%), and among 16-18-year old boys (from 4.2 to 9.9\%) and girls (6.9\% to 15.9\%). The prevalence of neck pain alone only increased in the 1990s (e.g. among 16-18-year-old girls $22.9 \%$ in 1991, 29.2\% in 1999, and 29.5\% in 2011), while the prevalence of low back pain alone remained relatively constant during the last two decades (e.g. among 16-18-year-old girls 4\% in 1991, 3.1\% in 1999, and 3.7\% in 2011).

Conclusions: Concomitant neck and low back pain has constantly increased in the last two decades among adolescents, while single neck pain has only increased in the 1990s. Single low back pain has remained relatively constant. Thus, earlier detected increase in low back pain in the 1990s was explained by the increase in concomitant neck and low back pain. Differences in the time trends in the three pain conditions might suggest, at least partly, different risk factors and aetiology for single- and multisite spinal pain among adolescents. This hypothesis needs further investigations.

Keywords: Neck pain, Low back pain, Concomitant neck and low back pain, Spinal pain, Musculoskeletal pain, Adolescent, Time trend, Serial cross-sectional design, Prevalence

\section{Background}

The prevalence of neck pain and, to a lesser extent, low back pain among children and adolescents increased in the late 20th century [1]. Given the postulated link between neck and back pain symptoms in childhood, adolescence, and adulthood, this might pose a future health

\footnotetext{
* Correspondence: minna.stahl@tampere.fi

'Department of Physical and Rehabilitation Medicine, Hatanpää Hospital, Hatanpäänkatu 24, PO Box 437, Tampere 33101, Finland

${ }^{2}$ University of Helsinki, Hjelt Institute, PO Box 40, Helsinki 00014, Finland

Full list of author information is available at the end of the article
}

challenge [2-5]. Whether this observed trend has continued in the new millennium is unknown.

The past two decades have witnessed changes in environmental exposures that could have influenced occurrence of neck and low back pain. Such potential changes among adolescents included unfavourable shifts in leisure-time activity patterns; decrease in physical activity and tremendous increase in the use of information and communication technology [6]. Such behavioural changes have been suggested to be contributing factors to the increased occurrence of neck and low back pain, mainly through an 
assumed increase in repetitive movements and static postures causing localised muscle fatigue and pain [7]. Furthermore, a secular increase has been noted in psychosomatic and stress symptoms, and sleep disturbances [8-10]. These changes might suggest a continuing increase in neck and low back pain in adolescents.

In earlier studies, time trends of neck and low back pain have been studied separately whereas changes in concomitant neck and low pain have not been studied. Neurobiological processing of negative emotions and pain resemble each other [11], and it has been suggested that frequent pain symptoms in childhood and adolescence should be considered a potential general pain disorder reflecting psychological stress, rather than merely a localised body disorder [12,13]. On the other hand, the Finnish twin studies among early adolescents showed that genetic factors play the most important role in the susceptibility to neck pain [14], whereas low back pain and widespread pain are related to common and unique environmental factors in early adolescence $[15,16]$. Based on this observation and taking into account changes in the risk factors it is possible that time trends in concomitant and single neck and low back pain differ from each other.

Altogether, only few studies have investigated adolescents' neck pain with other musculoskeletal pain. In a 4-year follow-up study of originally pain-free preadolescents, neck pain occurred more often with other musculoskeletal pain, most often with lower limb or axial pain, than as a single pain. [17]. In a cross-sectional study among 14-year-old Australians, single neck and low back pain were overall more common than concomitant neck and low back pain [18]. It is not clear, whether single and concomitant neck and low back pain are separate entities, overlap or occur consecutively in adolescents.

This study investigated time trends from 1991 to 2011 in three types of spinal pain: neck pain alone, low back pain alone, and concomitant neck and low back pain among 12 to 18 -year-old Finns.

\section{Methods}

\section{Subjects}

The Adolescent Health and Lifestyle Survey is an ongoing (since 1977) nationwide monitoring system on adolescent health and lifestyle in Finland. Data is collected every second year from 12 to 18-year-old Finns. Here we used data from 1991, 1999, 2001, 2003, 2005, 2007, 2009, and 2011, because only in all those surveys neck and low back pain were assessed with separate questions. The sampling strategy, and data collection methods were similar across the survey years. Samples of 12, 14, 16, and 18-year-old Finns (mean age 12.6, $14.6,16.6$, and 18.6 years) born on certain dates in July (in some age groups, dates from June and August were used to avoid using the same persons in different years) were drawn every survey year from the National Population Registry Centre. A questionnaire, that included multiple questions related to health and health behaviours, was sent in February with a return envelope and pre-paid postage. In 2009 and 2011, the option of completing the questionnaire through the Internet, using a personal username and password, was provided. Two additional attempts were made to contact non-respondents.

\section{Measurements}

Each survey year the questionnaire had approximately a hundred questions. The surveyed areas were health and health complaints, use of alcohol and tobacco products, physical activity, and sleep behaviour as well as socioeconomic background, family and school performance. The core areas were kept the same over the survey years while part of the questionnaire varied including e.g. violence, meal patterns, gambling or hopes and worries for the future. Each study year, the new questions added to the questionnaire were pretested in a sample of schoolchildren.

Each survey year the questionnaire included the following two questions about spinal pain: "Have you had low back pain during the past 6 months?" and " Have you had neck pain during the past 6 months?" In the latter question, the Finnish language refers to the anatomical area including the neck spine, occiput, and other structures covered by the upper trapezius muscles. Answer options for both questions were as follows: seldom or not at all, about once a month, about once a week, and almost daily. Both variables were dichotomised; pain frequency categories 'seldom or not at all' and 'about once a month' were merged and rephrased as 'no or infrequent pain', and 'about once a week' and 'daily pain' were also merged and rephrased as 'at least weekly pain'. The latter two phrases were merged mainly because of the very small number of respondents with daily symptoms. For analyses, four variables were created: 1 . No or occasional neck and low back pain 2. Neck pain alone at least weekly, 3. Low back pain alone at least weekly, and 4. Concomitant neck and low back pain at least weekly. Test-retest reliability of the questionnaire for detecting those reporting pain at least weekly was evaluated earlier in a subsample of 14-to 16-year-old adolescents from the 2003 cohort with a kappa coefficient of 0.56 for neck pain, and a similar coefficient of 0.56 for low back pain [7]. Other tests of validation were not performed. Our study follows the guidelines of STROBE (see Additional file 1).

\section{Analysis of non-respondents}

The possible effect of a decrease in response proportions on the prevalence of pain symptoms was investigated indirectly, since information from non-respondents was not available. The respondents were categorised into three groups based on how promptly they returned the 
Table 1 Number of respondents (N) and response proportion (\%) by survey year, gender and age

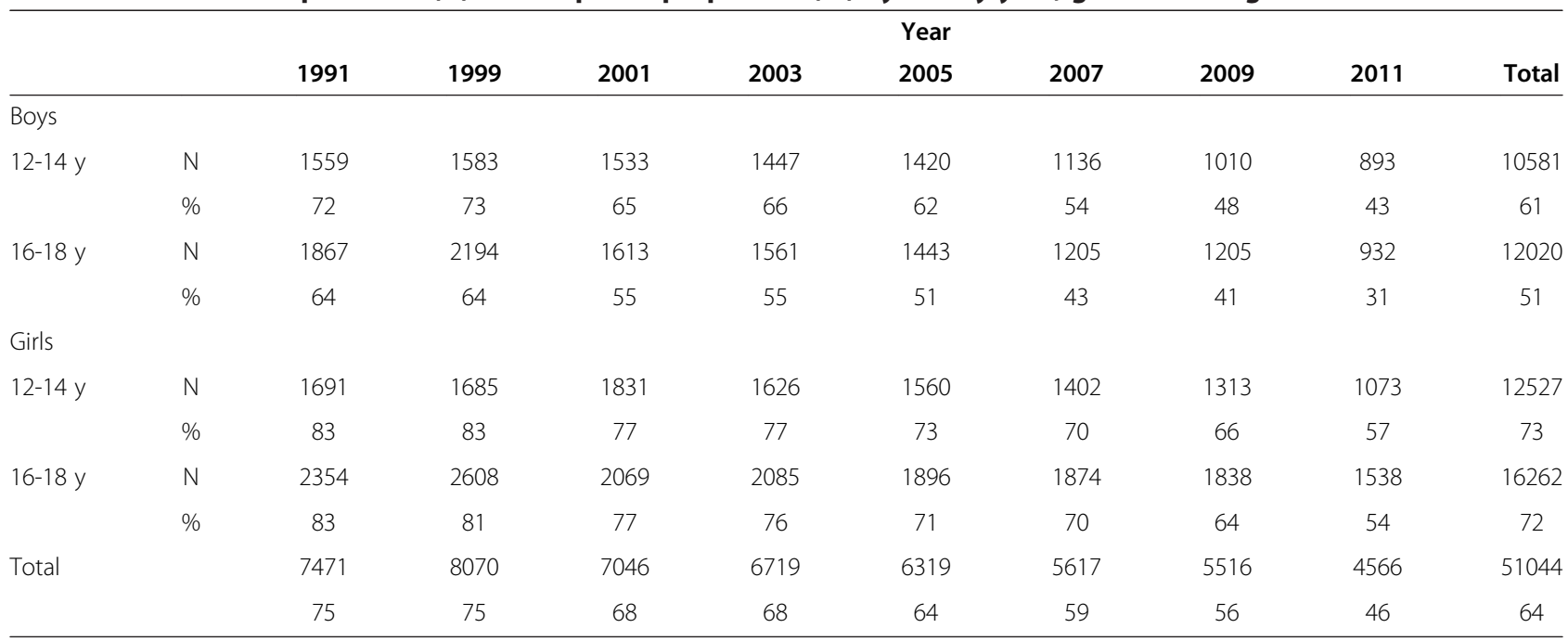

questionnaire (original, first re-inquiry, and second reinquiry). It was assumed that the later the person answered, the more he/she resembled a non-respondent. We used the years 1999, 2003, and 2011. Differences between the three respondent groups were small and not systematic over the years or over the age or gender groups.

\section{Ethics}

This study follows the ethical principles of the Declaration of Helsinki; subjects were informed of the aims, methods, voluntary participation, privacy, and confidentiality of the collected information. The study protocol was approved by the The Ethics Committee of Tampere Region (reference "Lausunto 2/2010).

Table 2 The prevalence (\%) of neck pain alone (NP), low back pain alone (LBP), and concomitant neck and low back pain (NLBP) by survey year, sex, and age

\begin{tabular}{|c|c|c|c|c|c|c|c|c|c|}
\hline \multicolumn{9}{|c|}{ Survey year } & \multirow{2}{*}{$\begin{array}{l}\text { *P for linear } \\
\text { trend }\end{array}$} \\
\hline & 1991 & 1999 & 2001 & 2003 & 2005 & 2007 & 2009 & 2011 & \\
\hline \multicolumn{10}{|l|}{ Boys } \\
\hline \multicolumn{10}{|l|}{$12-14$} \\
\hline NP alone & 4.8 & 6.2 & 8.4 & 7.9 & 8.0 & 8.2 & 9.9 & 5.9 & $<0.001$ \\
\hline LBP alone & 3.3 & 2.5 & 3.3 & 3.3 & 2.8 & 3.0 & 4.8 & 3.8 & 0.11 \\
\hline NLBP & 1.6 & 2.8 & 2.5 & 2.3 & 3.5 & 5.6 & 5.5 & 3.8 & $<0.001$ \\
\hline \multicolumn{10}{|l|}{$16-18$} \\
\hline NP alone & 7.1 & 9.3 & 11.7 & 10.4 & 10.5 & 9.6 & 11.2 & 10.7 & $<0.001$ \\
\hline LBP alone & 5.4 & 4.6 & 6.1 & 6.1 & 5.9 & 6.1 & 6.6 & 6.9 & 0.008 \\
\hline NLBP & 4.2 & 5.7 & 6.0 & 7.5 & 8.0 & 9.1 & 8.6 & 9.9 & $<0.001$ \\
\hline \multicolumn{10}{|l|}{ Girls } \\
\hline \multicolumn{10}{|l|}{$12-14$} \\
\hline NP alone & 11.1 & 18.2 & 17.5 & 15.9 & 18.9 & 16.8 & 16.6 & 18.5 & $<0.001$ \\
\hline LBP alone & 2.7 & 2.3 & 2.5 & 2.3 & 3.1 & 3.2 & 3.9 & 3.0 & 0.023 \\
\hline NLBP & 2.0 & 4.2 & 4.8 & 3.4 & 5.1 & 7.5 & 6.8 & 7.5 & $<0.001$ \\
\hline \multicolumn{10}{|l|}{$16-18$} \\
\hline NP alone & 22.7 & 29.2 & 30.2 & 29.3 & 29.3 & 30.9 & 28.3 & 29.5 & $<0.000$ \\
\hline LBP alone & 4.0 & 3.1 & 4.5 & 3.7 & 3.9 & 3.7 & 4.4 & 3.7 & 0.060 \\
\hline NLBP & 6.9 & 10.1 & 10.9 & 11.3 & 13.5 & 15.1 & 17.4 & 15.9 & $<0.000$ \\
\hline
\end{tabular}

Level of significance for linear trends is shown with P-values. 


\section{Statistical methods}

Descriptive values are shown in prevalence proportions (\%) with 95\% confidence intervals. Generalized linear models with appropriate distribution and link function was used to check the statistical significance of the linearity of trends in the three pain groups. The time difference between the surveys years was taken into account. Relative rates were estimated by using generalized linear models with binomial family and log link. The prevalence of neck pain alone, low back pain alone and concomitant neck and low back pain in 1991 was used as a reference in calculating the relative risks for the pains in 1999, and in 2011.

\section{Results}

Table 1 shows the number of respondents for each survey year by age and gender. Response proportions ranged between $75 \%$ in 1991 to $46 \%$ in 2011 with a mean percentage of $64 \%$ for all assessments combined. Response proportions were generally higher for girls than for boys regardless of age.
Table 2 and Figure 1 illustrate the changes in the prevalence of neck pain alone, low back pain alone, and concomitant neck and low back pain from 1991 to 2011 by age and gender. All three types of pain were more common among girls than boys, and among older adolescents compared to younger ones in all eight surveys. Neck pain alone was the most common in all age and gender groups in all surveys. Statistically significant linearity was observed in all trends in neck pain alone, and concomitant neck and low back pain, but only in half of the trends in low back pain alone (Table 2). However, a closer observation (Tables 2 and 3, and Figure 1) shows that the prevalence of neck pain alone increased from 1991 to 1999 in girls and to 2001 in boys, after which the trend levelled off. The increasing trend in concomitant neck and low back pain continued through the whole study period to 2009/2011 in all age and gender groups. Table 3 shows the relative risks (RR) for different pains in 1999 and in 2011 compared to the reference year 1991. From 1991 to 2011 the prevalence of concomitant neck and low back pain almost quadrupled

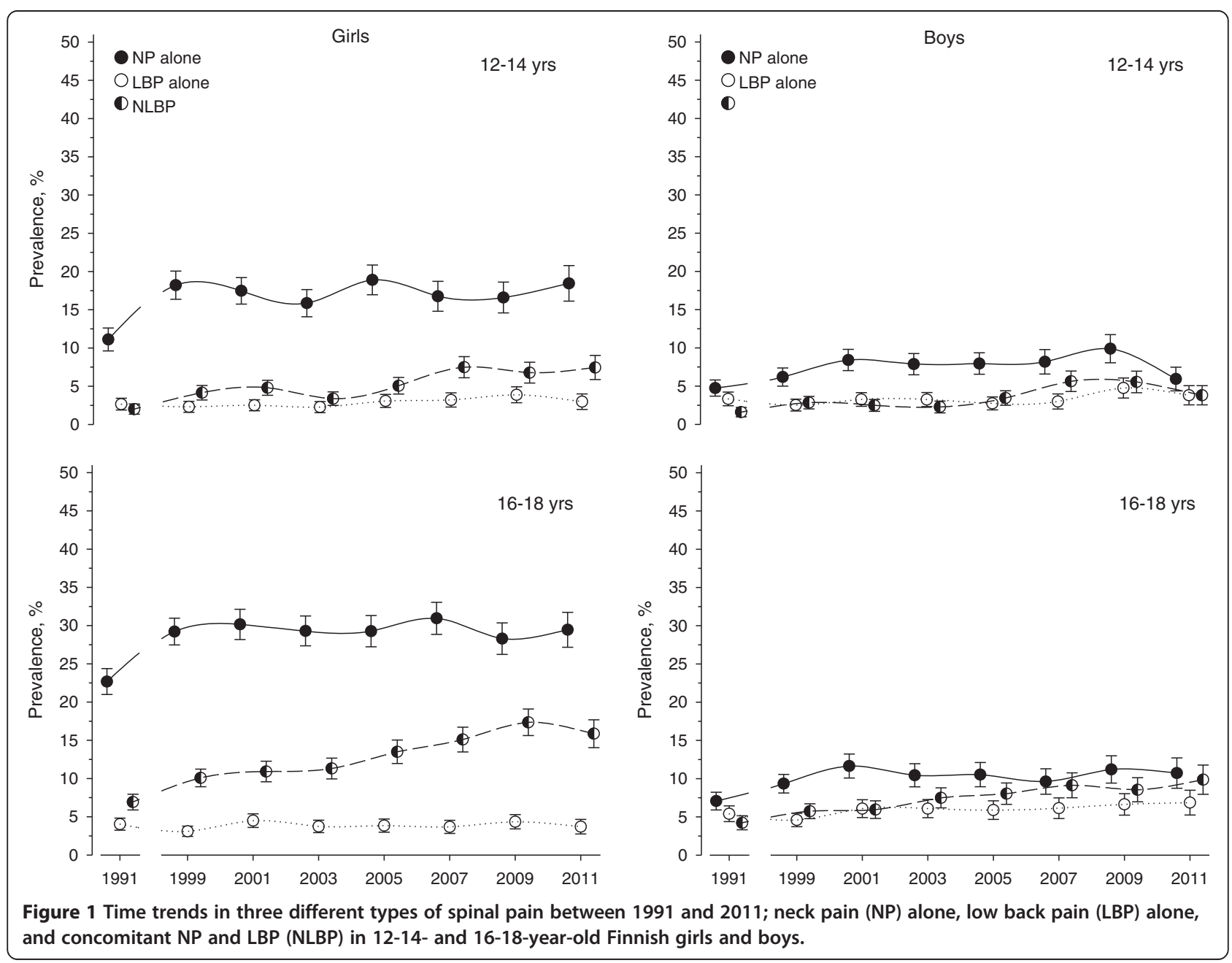


Table 3 Relative risks (RR) for neck pain alone (NP), low back pain alone (LBP), and concomitant neck and low back pain (NLBP) in 1999, and in 2011 compared to the reference year 1991

\begin{tabular}{|c|c|c|}
\hline & $\begin{array}{c}\text { RR }(95 \% \mathrm{Cl}) \text { for pain } \\
\text { in } 1999 \text { compared } \\
\text { to } 1991 \text { (RR 1.00) }\end{array}$ & $\begin{array}{c}\text { RR }(95 \% \mathrm{Cl}) \text { for pain } \\
\text { in } 2011 \text { compared } \\
\text { to } 1991 \text { (RR 1.00) } \\
\end{array}$ \\
\hline \multicolumn{3}{|l|}{ NP alone } \\
\hline \multicolumn{3}{|l|}{ Boys } \\
\hline $12-14$ & $1.30(0.97$ to 1.75$)$ & 1.25 (0.89 to 1.76$)$ \\
\hline $16-18$ & 1.32 (1.07 to 1.63$)$ & 1.52 (1.18 to 1.94$)$ \\
\hline \multicolumn{3}{|l|}{ Girls } \\
\hline $12-14$ & 1.64 (1.38 to 1.94$)$ & 1.66 (1.38 to 2.00$)$ \\
\hline $16-18$ & 1.29 (1.17 to 1.42$)$ & 1.30 (1.17 to 1.45$)$ \\
\hline \multicolumn{3}{|l|}{ LBP alone } \\
\hline \multicolumn{3}{|l|}{ Boys } \\
\hline $12-14$ & 0.76 (0.50 to 1.14$)$ & 1.14 (0.75 to 1.75$)$ \\
\hline $16-18$ & 0.85 (0.65 to 1.11$)$ & 1.27 (0.94 to 1.72$)$ \\
\hline \multicolumn{3}{|l|}{ Girls } \\
\hline $12-14$ & 0.87 (0.57 to 1.33 ) & $1.12(0.72$ to 1.75$)$ \\
\hline $16-18$ & 0.77 (0.58 to 1.03$)$ & 0.92 (0.67 to 1.27$)$ \\
\hline \multicolumn{3}{|l|}{ NLBP } \\
\hline \multicolumn{3}{|l|}{ Boys } \\
\hline $12-14$ & 1.77 (1.09 to 2.87 ) & 2.37 (1.42 to 3.95$)$ \\
\hline $16-18$ & 1.36 (1.03 to 1.79$)$ & 2.33 (1.75 to 3.12 ) \\
\hline \multicolumn{3}{|l|}{ Girls } \\
\hline $12-14$ & 2.07 (1.38 to 3.10$)$ & 3.71 (2.50 to 5.50$)$ \\
\hline $16-18$ & 1.46 (1.21 to 1.76$)$ & 2.29 (1.90 to 2.76$)$ \\
\hline
\end{tabular}

Calculations are based on the prevalences presented in Table 2 .

among 12 to 14-year-old girls (RR 3.7), and more than doubled among other groups (RR 2.4 among 12-14-yearold boys, and RR 2.3 among 16-18-year-old boys and girls). The prevalence of low back pain alone remained fairly unchanged over the study period in all age and gender groups.

\section{Discussion}

The findings of the present study show a steady increase in the prevalence of concomitant neck and low back pain among adolescents over the last 20 years. Prevalence of neck pain alone increased only in the 1990s, whereas the prevalence of low back pain alone has remained quite stable over the past two decades.

The strengths of the present study are its fully comparable eight cross-sectional surveys over the last two decades allowing an exploration of time trends in a large and representative sample of adolescents. The symptoms, across surveys, were asked at the same time of the year; thus, the fluctuation of symptoms due to seasonal variation was excluded [19]. In addition, the frequency of neck and low back pain during the past six months was assessed, so the results refer to frequent and persistent spinal morbidities (i.e., excluding occasional pain such as menstruation pain). Since neck and low back pain were asked about only with one combined question in 1993, 1995 and 1997, data from these years could not be used in this study. The constant decrease in response proportions over the study years, especially among boys, is another limitation that might have had an influence on the reliability of the prevalence figures and estimated odds ratios. Information about the non-respondents would have been needed in order to exclude a potential selection bias. However, we did not have any information about the non-respondents, but instead attempted to indirectly investigate its potential effect by comparing the three different groups of respondents on how promptly they had returned the questionnaire (original, first reinquiry, and second re-inquiry) with an assumption that the later the person answered, the more he/she resembled a non-respondent. Although the validity of this assumption can be discussed, our findings did not give any support for a potential selection bias, with non-significant differences in pain prevalence between early and late respondents. Several other methodological issues might have affected the internal validity of the study. The test-retest reliability of the pain questions over three weeks was only moderate [20]. In addition, the six-month recall period was quite long taking into account the fluctuating natural course of at least neck pain [5], which may have led to difficulties in frequency classification of the symptoms. Since there was no pain mannequin alongside the pain questions, the neck pain alone group might contain those who have only upper back pain, and those with concomitant neck and upper back pain.

To our knowledge, this is the first study presenting time trends for single versus concomitant neck and low back pain in adolescents. The increasing trend in low back pain in the late 20th century reported by Hakala et al. [1] was thus explained by the increase in concomitant neck and low back pain. The prevalence of all three types of spinal pain increased with age and was more common in girls than in boys, consistent with previous reports [5,21-23]. A systemic overview of the research literature on epidemiology of adolescent spinal pain concluded that the comparison of the studies is difficult due to great variety of different pain definitions and outcome measurements [21]. We did not find any other studies that used the same pain definitions and recall period used in our study. The only other study that has investigated the prevalence of single versus concomitant neck and low back pain without asking other musculoskeletal pain was conducted by Rees et al. [17]. They investigated the 1-month period prevalence of single and concomitant neck and low back pain among 1580 (98\%) 14-year- 
old Australians in 2000s. The prevalence of neck pain only was $17 \%$, back pain only $13 \%$, and concomitant neck and back pain was $18 \%$ among girls. Corresponding proportions among boys were $14 \%, 17 \%$ and $9 \%$.

Our finding of an increased occurrence of concomitant neck and low back pain and a more constant occurrence of neck pain alone or low back pain alone during the last two decades could be explained by at least partly different underlying aetiologies for the two types of pain. First, the increase in concomitant pain could reflect the changes in the contemporary adolescents' life, such as an increase in computer use [6], sleep difficulties [10], and a decrease in psychosocial wellbeing $[8,9]$, all of which have been found risk factors for low back and neck pain [3,5,7,24-28]. The results of Rees et al. [18] support this hypothesis; concomitant neck and low back pain was associated significantly more with mental health problems than single neck and single low back pain. Second, the prevalence of neck pain alone or low back pain alone were fairly constant over the last 20 years, which could be linked to familial factors, i.e., genetic and common environmental factors, which remain more stable over time $[14,15]$. Future studies aimed at investigating whether these two types of spinal pain are truly separate entities or whether they overlap or occur consecutively are needed. Furthermore, future studies should be aimed at understanding the factors that underlie the increase in concomitant neck and back pain, rather than factors that only underlie either neck or back pain.

\section{Conclusion}

The prevalence of concomitant neck and low back pain has steadily increased over the past 20 years, while the prevalence of neck pain alone has increased only in the 1990s. The prevalence of low back pain alone has remained quite stable. Our findings suggest that the underlying aetiology for single and concomitant neck and low back pain in adolescents might, at least partly, differ. Future studies should be aimed at investigating this hypothesis more closely, and especially in relation to already identified risk factors for adolescent neck and low back pain.

\section{Additional file}

Additional file 1: STROBE Statement-Checklist of items that should be included in reports of cross-sectional studies ( $X=$ done, $N / A=$ not applicable).

\section{Competing interests}

The authors declare that they have no competing interests.

\section{Authors' contributions}

AR was responsible for the conception and design of the initial study. MS, AEM, and AR formulated the study questions and interpreted the data. MS drafted the article and all the other authors discussed the results and contributed to the critical revision of the manuscript for important intellectual content. All authors made the final approval of the version to be published.

\section{Acknowledgements}

We thank Mr. Lasse Pere, School of Health Sciences University of Tampere, for data processing and analyses.

\section{Author details}

'Department of Physical and Rehabilitation Medicine, Hatanpää Hospital, Hatanpäänkatu 24, PO Box 437, Tampere 33101, Finland. University of Helsinki, Hjelt Institute, PO Box 40, Helsinki 00014, Finland. ${ }^{3}$ Department of Epidemiology and Biostatistics, College of Public Health, King Saud Bin Abdulaziz University for Health Sciences, PO Box 22490, Riyadh 11426, Saudi Arabia. ${ }^{4}$ Aberdeen Pain Research Collaboration (Epidemiology Group), Institute of Applied Health Sciences, University of Aberdeen, Aberdeen AB25 2ZD, UK. ${ }^{5}$ School of Health Sciences, University of Tampere, Tampere 33014, Finland. ${ }^{6}$ Department of Adolescent Psychiatry, Tampere University Hospital, Pitkäniemi Hospital, Pitkäniemi 33380, Finland.

Received: 5 March 2014 Accepted: 3 September 2014 Published: 5 September 2014

\section{References}

1. Hakala P, Rimpelä A, Salminen JJ, Virtanen SM, Rimpela M: Back, neck, and shoulder pain in Finnish adolescents: national cross sectional surveys. BMJ 2002, 325:743-745.

2. Brattberg G: Do pain problems in young school children persist into early adulthood? A 13-year follow-up. Eur J Pain 2004, 8:187-199.

3. Siivola SM, Levoska S, Latvala K, Hoskio E, Vanharanta H, Keinanen-Kiukaanniemi S: Predictive factors for neck and shoulder pain: a longitudinal study in young adults. Spine 2004, 29:1662-1669.

4. Hestbaek L, Leboeuf-Yde C, Kyvik KO, Manniche C: The course of low back pain from adolescence to adulthood: eight-year follow-up of 9600 twins. Spine 2006, 31:468-472.

5. Ståhl M, Kautiainen H, El-Metwally A, Häkkinen A, Ylinen J, Salminen JJ, Mikkelsson M: Non-specific neck pain in schoolchildren: prognosis and risk factors for occurrence and persistence. A 4-year follow-up study. Pain 2008, 137:316-322

6. Nelson MC, Neumark-Stzainer D, Hannan PJ, Sirard JR, Story M: Longitudinal and secular trends in physical activity and sedentary behavior during adolescence. Pediatrics 2006, 118:e1627-e1634.

7. Hakala PT, Rimpelä AH, Saarni LA, Salminen JJ: Frequent computer-related activities increase the risk of neck-shoulder and low back pain in adolescents. Eur J Public Health 2006, 16:536-541.

8. Karvonen S, Vikat A, Rimpelä M: The role of school context in the increase in young people's health complaints in Finland. J Adolesc 2005, 28:1-16.

9. School Health Promotion Study 2011: Changes in living and school conditions, health and health habits in Finnish schoolchildren from 2000/2001 to 2010/2011. (Kouluterveyskyselyn tuloksia nuorten elinoloista, kouluoloista, terveydestä, terveystottumuksista sekä oppilas- ja opiskelijahuollosta vuosina 2000/2001 - 2010/2011) http://info.stakes.fi/kouluterveyskysely/FI/ tulokset/index.htm.

10. Pallesen S, Hetland J, Sivertsen B, Samdal O, Torsheim T, Nordhus $\mid H$ : Time trends in sleep-onset difficulties among Norwegian adolescents: 1983-2005. Scand J Public Health 2008, 36:889-895.

11. Mollet GA, Harrison DW: Emotion and pain: a functional cerebral systems integration. Neuropsychol Rev 2006, 16:99-121.

12. Petersen $\mathrm{S}$, Brulin C, Bergstrom E: Recurrent pain symptoms in young schoolchildren are often multiple. Pain 2006, 121:145-150.

13. Carnes D, Parsons S, Ashby D, Breen A, Foster NE, Pincus T, Vogel S, Underwood M: Chronic musculoskeletal pain rarely presents in a single body site: results from a UK population study. Rheumatology 2004, 46:1168-1170.

14. Ståhl MK, El-Metwally AA, Mikkelsson MK, Salminen JJ, Pulkkinen LR, Rose RJ, Kaprio JA: Genetic and environmental influences on non-specific neck pain in early adolescence: A classical twin study. Eur J Pain 2013, 17:791-798.

15. El-Metwally A, Mikkelsson M, Ståhl M, Macfarlane GJ, Jones GT, Pulkkinen L, Rose RJ, Kaprio J: Genetic and environmental influences on non-specific low back pain in children: a twin study. Eur Spine J 2008, 17:502-508. 
16. Mikkelsson M, Kaprio J, Salminen JJ, Pulkkinen L, Rose R: Widespread pain among 11-year-old Finnish twin pairs. Arthritis Rheum 2001, 44:481-485.

17. Ståhl M, Mikkelsson M, Kautiainen H, Häkkinen A, Ylinen J, Salminen JJ: Neck pain in adolescence. A 4-year follow-up of pain-free preadolescents. Pain 2004, 110:427-431.

18. Rees CS, Smith AJ, O'Sullivan PB, Kendall GE, Straker LM: Back and neck pain are related to mental health problems in adolescence. BMC Public Health 2011, 1:382.

19. Takala EP, Viikari-Juntura E, Moneta GB, Saarenmaa K, Kaivanto K: Seasonal variation in neck and shoulder symptoms. Scan J Work Environ Health 1992, 18:257-261.

20. Landis JR, Koch GG: The measurement of observer agreement for categorical data. Biometrics 1977, 33:159-174

21. Jeffries LJ, Milanese SF, Grimmer-Somers KA: Epidemiology of adolescent spinal pain: a systematic overview of the research literature. Spine 2007, 32:2630-2637

22. Kjaer $P$, Wedderkopp N, Korsholm L, Leboeuf-Yde C: Prevalence and tracking of back pain from childhood to adolescence. BMC Musculoskelet Disord 2011, 12:98.

23. Auvinen JP, Paananen MV, Tammelin TH, Taimela SP, Mutanen PO, Zitting PJ, Karppinen Jl: Musculoskeletal pain combinations in adolescents. Spine 2009, 34:1192-1197.

24. Härmä AM, Kaltiala-Heino R, Rimpelä M, Rantanen P: Are adolescents with frequent pain symptoms more depressed? Scan J Prim Health Care 2002, 20:92-96.

25. Szpalski M, Gunzburg R, Balague F, Nordin M, Melot C: A 2-year prospective longitudinal study on low back pain in primary school children. Eur Spine J 2002, 11:459-464.

26. Diepenmaat AC, van der Wal MF, de Vet HC, Hirasing RA: Neck/shoulder, low back, and arm pain in relation to computer use, physical activity, stress, and depression among Dutch adolescents. Pediatrics 2006, 117:412-416.

27. Prins $Y$, Crous $L$, Louw QA: A systematic review of posture and psychosocial factors as contributors to upper quadrant musculoskeletal pain in children and adolescents. Physiother Theory Pract 2008, 24:221-242.

28. Auvinen JP, Tammelin TH, Taimela SP, Zitting PJ, Jarvelin MR, Taanila AM, Karppinen Jl: Is insufficient quantity and quality of sleep a risk factor for neck, shoulder and low back pain? A longitudinal study among adolescents. Eur Spine J 2010, 19:641-649.

doi:10.1186/1471-2474-15-296

Cite this article as: Ståhl et al:: Time trends in single versus concomitant neck and back pain in finnish adolescents: results from national cross-sectional surveys from 1991 to 2011. BMC Musculoskeletal Disorders 2014 15:296.

\section{Submit your next manuscript to BioMed Central and take full advantage of:}

- Convenient online submission

- Thorough peer review

- No space constraints or color figure charges

- Immediate publication on acceptance

- Inclusion in PubMed, CAS, Scopus and Google Scholar

- Research which is freely available for redistribution

Submit your manuscript at www.biomedcentral.com/submit 